\title{
Design, Synthesis and Biological Evaluation of Strigolactone and Strigolactam Derivatives for Potential Crop Enhancement Applications in Modern Agriculture
}

\author{
Alain De Mesmaeker ${ }^{\star \star a}$, Claudio Screpanti§a ${ }^{\S}$ Raymonde Fonné-Pfister ${ }^{\S a}$, Mathilde Lachiaa, \\ Alexandre Lumbroso ${ }^{a}$, Harro Bouwmeester ${ }^{\text {sb }}$
}

§Sandmeyer Award 2018

\begin{abstract}
Strigolactones have been known as signaling molecules in the rhizosphere of plants since more than 50 years. However, their roles as phytohormone have been only recognized since 2008 . We describe here a very efficient synthetic access to representative canonical strigolactones displaying the A-B-C-D tetracyclic structure and to non-canonical strigolactones as carlactonoic acid and methyl carlactonoate. In addition, we report the design and the synthesis of strigolactams as promising derivatives of strigolactones for potential use in modern agriculture. Among the synthetic methods developed for this project, the intramolecular [2+2] cycloaddition of keteneiminium salts to $\mathrm{C}=\mathrm{C}$ bond has been particularly useful to the synthesis of natural strigolactones and their potentially improved analogues.
\end{abstract}

Keywords: Crop enhancement · Keteneiminium salts · Seed germination · Strigolactones · Total synthesis



Alain De Mesmaeker obtained his $\mathrm{PhD}$ in Organic Chemistry from the Catholic University of Louvain, Belgium in 1983. Following a postdoctoral research at the Weizmann Institute, Israel, he joined in 1985 the Central Research Laboratories of Ciba-Geigy, Basel, Switzerland. In 1997 he moved to Novartis Crop Protection, which became Syngenta in 2000, where he was Head of Research Chemistry. He initiated his work on strigolactones in 2008. He is a Principal Syngenta Fellow and the President of the Swiss Chemical Society.

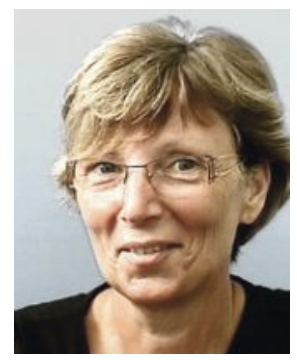

Raymonde Fonné-Pfister received her $\mathrm{PhD}$ in Plant Biochemistry from the University of Strasbourg in 1985. Following a postdoctoral research position at the Basel Biocenter in Switzerland, she joined the Agricultural division from Ciba-Geigy, Basel, Switzerland in 1988. In 1997 she moved to Novartis Crop Protection, which became Syngenta in 2000, where she is Syngenta Fellow since 2003 and working in Abiotic Stress and Crop Enhancement Research Biology.

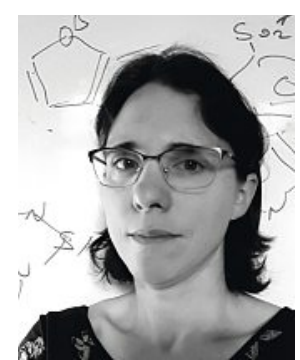

Mathilde Lachia studied chemistry at Ecole Polytechnique in France before completing a $\mathrm{PhD}$ in organic chemistry at the University of Nottingham working on the synthesis of natural product Diazonamide A. She then joined Syngenta Crop Protection to work on plant hormones and abiotic stress control. She has a strong interest in natural products and plant biology and is currently a team leader and project leader for abiotic stress control.

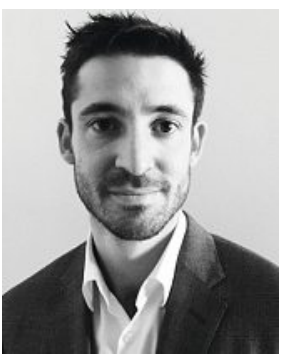

Alexandre Lumbroso studied chemistry at the University of Nantes (France) before completing a $\mathrm{PhD}$ (2009) in organic chemistry in the group of Prof. Jean-Paul Quintard working on the use of organostannes for the stereoselective synthesis of glycosidases inhibitors. He then moved to the group of Prof. Bernhard Breit in 2010 at the University of Freiburg im Breisgau (Germany) working on the development of new atomic-economic rhodium-catalyzed reactions. In 2013, Alexandre Lumbroso joined Syngenta Crop Protection as postdoc before being appointed Team Leader in 2014 working on plant hormones and abiotic stress control as well as in fungicide lead generation. 


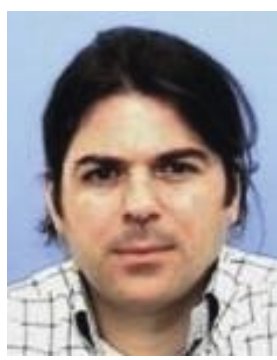

Claudio Screpanti obtained his $\mathrm{PhD}$ in Agronomy from the University of Bologna, Italy in 2004. He carried out additional studies in molecular biology and genetic engineering at the University of Louvainla-Neuve, Belgium. In 2005 he joined the Syngenta R\&D organization. In 2018 he became Syngenta Fellow. In his current role, he leads the Soil Competence Centre and acts as Syngenta soil expert looking at the soil behavior of new small molecules. The aim is to discover and develop new and more sustainable crop protection solutions.

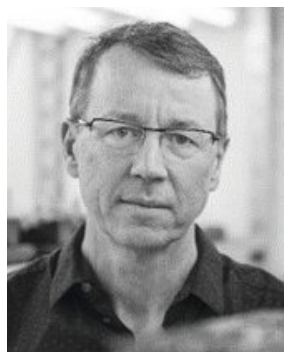

Harro Bouwmeester obtained his $\mathrm{PhD}$ in Plant Physiology from Wageningen University, the Netherlands in 1990. After postdoctoral and research scientist appointments in several research institutes in Wageningen, he became Chair of Plant Physiology at Wageningen University (2008). Since 2016 he is Chair of Plant Hormone Biology at the Swammerdam Institute for Life Sciences (SILS) of the University of Amsterdam, the Netherlands. The work in his group is centered on signaling molecules and their role in the chemical communication of plants with other organisms.

\section{Introduction}

The present publication summarizes some of the pioneering work performed at Syngenta on the synthesis of natural strigolactones and on the design and synthesis of novel improved analogues of strigolactones, such as the strigolactams, together with the development of various assays to evaluate their performance as crop enhancing compounds. This work has been strongly reinforced through the collaboration with $\mathrm{H}$. Bouwmeester, who contributed to uncovering the signaling of strigolactones in the rhizosphere as well as in planta, demonstrating their multiple roles as the most recently identified phytohormone. Strigolactones have been the subject of very intensive work in plant sciences globally and it became clear that these substances offer a real potential for Crop Enhancement applications to modern agriculture.

\section{Total crop production worldwide (2014/2015)}

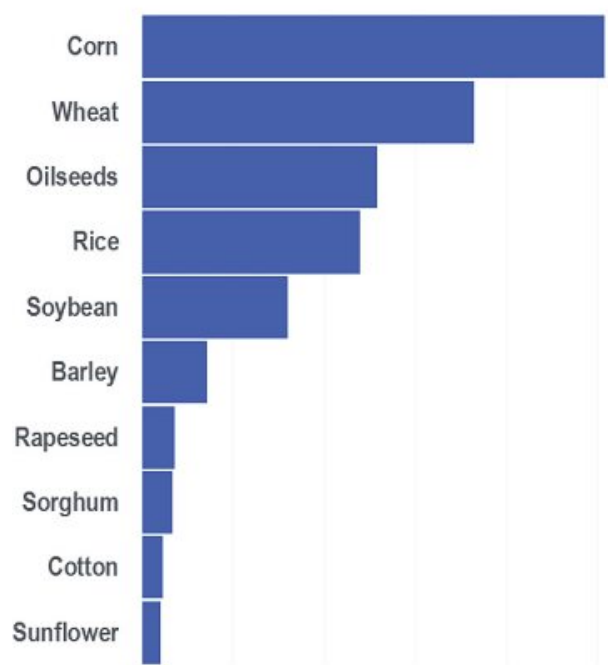

\section{Crop Enhancement Technologies for a Modern and Sustainable Agriculture}

Food and fiber production are currently threatened by a wide range of abiotic and biotic stresses. ${ }^{[1]}$ Past advances in plant breeding, plant biotech and crop protection solutions have enabled increasing food demands to keep pace in terms of quantity and quality. ${ }^{[1 a]}$ Yet, in recent years a more sustainable production system has become a priority for society, policy and food value chain agendas as reflected in the Sustainable Global Goals of the United Nation Organization. ${ }^{[2]}$

Thus, new innovation opportunities arose by developing new and modern crop protection solutions aimed at mitigating abiotic stresses and simultaneously promoting key processes that support crop production by limiting external inputs. The broad range of effects of strigolactones both on plant development and on the regulation of critical rhizosphere processes make this new class of phytohormones particularly interesting for crop enhancement applications targeting a more sustainable agriculture. ${ }^{[3]}$

The major challenge in this new area of plant science remains the large discrepancy between the most studied plant model species in academic research and the most relevant staple crops worldwide as indicated in Fig. 1. There is a substantial knowledge gap on relevant crops. Thus, we had to devote significant efforts to establish the 'proof of concept' that strigolactone derivatives could favor crop growth under various agronomic conditions. We have focused our studies on crop plants such as corn, wheat and sunflower and some related abiotic and biotic stresses. This required the development of all biochemical and biological tests with the appropriate targets from in vitro up to greenhouse, semifield up to field tests. In addition, we had to design efficient and stereoselective syntheses of representative strigolactones ${ }^{[4]}$ and ultimately design improved analogues displaying favorable agronomic performance. In the following chapters we summarized some of our achievements during the proof-of-concept/discovery phase of the strigolactone work in Syngenta in collaboration with the group of $\mathrm{H}$. Bouwmeester.

\section{Discovery of Strigolactones as Phytohormones and their Potential for Crop Enhancement Applications}

The first strigolactone, isolated from cotton root exudate, was identified as (+) strigol 1 in 1966 (Fig. 2). ${ }^{[6]}$ Strigol was the

\section{Most used plant species in Strigolactones Research}

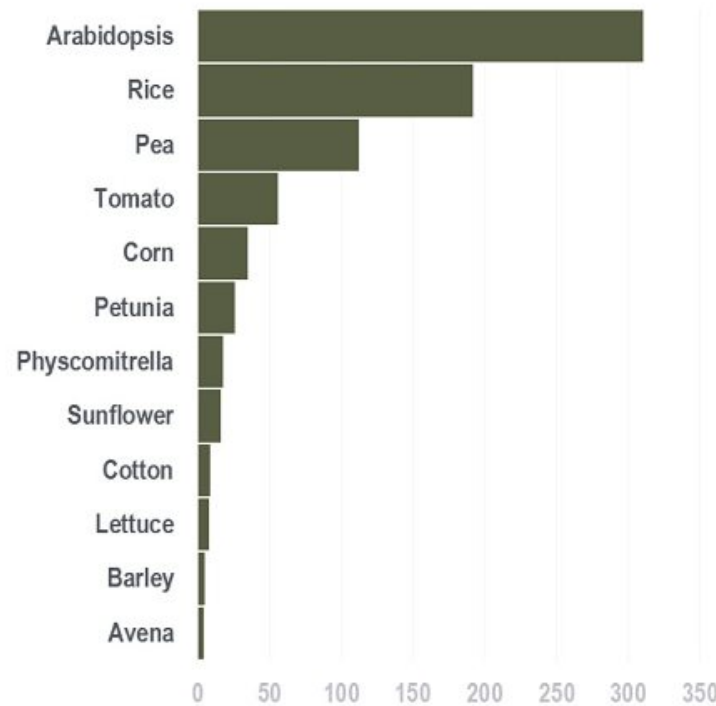

Fig. 1. Comparison between the most important crops and the most studied species in strigolactones research..$^{[5]}$ 
first member of a larger family of plant-produced compounds, namely the strigolactones, the molecular signal in the rhizosphere stimulating the germination of parasitic weeds from the $\underline{\text { Striga }}$, Orobanche, Phelipanche and Alectra genera. ${ }^{[7]}$ Since then it has been found that almost all land plants, including higher plants as well as non-vascular plants such as mosses, liverworts and stoneworts, produce a blend of several strigolactones (typically 3-6 usually related structures with sometimes different stereochemistry) in very low concentration (pico molar).

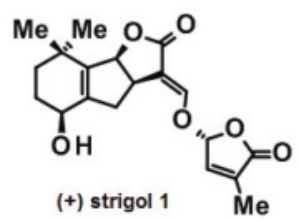

Fig. 2. (+) Strigol 1 is the first example of a strigolactone isolated from cotton root exudates. ${ }^{[6]}$

Several important crops suffer from infection by these root parasitic weeds, which leads to severe yield losses, causing dramatic depletion of food production in contaminated areas in Asia, Africa and the Mediterranean and black sea regions. ${ }^{[7 \mathrm{a}-\mathrm{f}, 8]}$ Moreover, sunflower is the target crop for Orobanche cumana parasitic weed (broomrape) in Europe and in the Black Sea area where a large part of global production is achieved. The decontamination of infested land has been attempted with some success by treatment with strigolactones prior to sowing the crop, inducing the suicidal germination of the parasitic weeds. ${ }^{[7 \mathrm{a}-\mathrm{f}, 8,8]}$ However, this strategy requires strigolactone derivatives having longer soil persistence and appropriate bioavailability to become successful. ${ }^{[10]}$ This could potentially be achieved by using strigolactam derivatives.

For many years, it remained unclear why plants exude strigolactones from their roots with the risk to stimulate infection by parasitic weeds. In 2005, Akiyama et al. reported that strigolactones are the signal in the rhizosphere that stimulates the hyphal branching of AM fungi (arbuscular mycorrhizal fungi), a process preceding the association of the fungus with the plant root forming a largely extended root network which facilitates the uptake of minerals and water by the plant.[11] The symbiosis with AM fungi enabled plants to migrate from water to land about 400 million years ago. Treatment of plants with strigolactone derivatives could potentially favor their association with AM fungi and stimulate their growth, especially under suboptimal conditions such as drought and low soil nutrients content. Strigolactone derivatives could be used in agronomy to stimulate not only growth but also to protect plants against pathogenic fungi and insects. ${ }^{[11,12]}$

Until 2008, strigolactones were considered as very potent rhizosphere signals. In 2008, two publications from Umehara et al. and Gomez-Roldan et al. disclosed that strigolactones are also acting as phytohormones, preventing the outgrowth of lateral branches in rice, pea and Arabidopsis. ${ }^{[13]}$ This suggested that strigolactone derivatives could be used at very low concentration to control plant architecture and, consequently, their growth. Due to the very high intrinsic activity of strigolactones in vitro, we could anticipate to reach good biological performance under agronomically relevant conditions with application rates as low as 5-20 grams/hectare, which would be economically very favorable and highly desirable for environmental and human safety considerations. These highly promising findings on strigolactones have stimulated very intensive research in various academic laboratories, as well as in industry, which uncovered their various roles in planta and in soil (Fig. 3). ${ }^{[3,7 \mathrm{~g}, 14]}$

Strigolactones stimulate germination of parasitic and nonparasitic seeds, ${ }^{[15]}$ participate to the nodulation of roots, stimulate seedling establishment and plant growth, shape root and plant architecture, induce leaf senescence to optimize nutrients reallocation, increase stem thickness and water distribution in tissues and number of seeds formation and overall yield. Recent findings suggested that strigolactones can influence the rhizosphere community composition. ${ }^{[16]}$ However, most of these data are generated on non-crop field plants such as Arabidopsis, petunia and pea. This does not reflect the needs in major crop plants for potential agronomic applications (Fig. 1) .

\section{Canonical and Non-canonical Natural Strigolactones}

Strigolactones are biosynthesized, mainly in roots but also to some extent in other plant tissues, from $\beta$-carotene leading to car-



Fig. 3. Roles of strigolactones in promoting crop enhancement effects, weeds and pest management and increasing soil resources efficiency. 
Fig. 4. Structures of representative canonical strigolactones having the A-B-C-D rings structure and of non-canonical strigolactones displaying only one ring in addition to the conserved D-ring. ${ }^{[3,79,14,17,18]}$
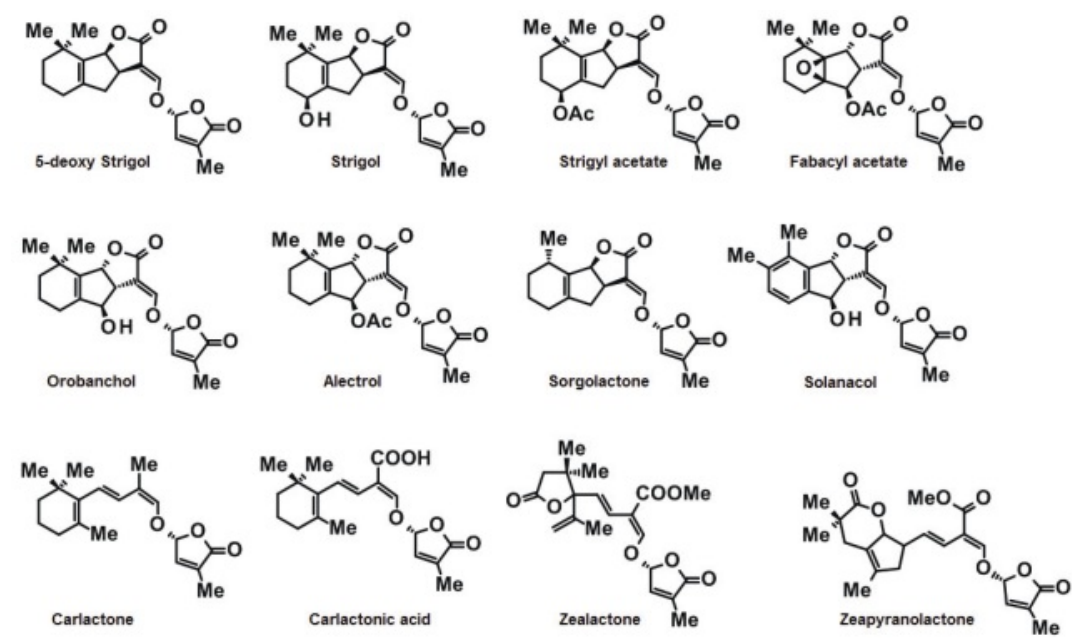

lactone, methyl carlactonoate and carlactonoic acid as key intermediates. ${ }^{[17]}$ At least 25 different canonical strigolactones having the A-B-C-D rings structure have been identified and are derivatives of 5-deoxystrigol or 4-deoxyorobanchol (Fig. 4).[14c,f,17]

Recently non-canonical strigolactones have been identified that possess modified structures arising from carlactonoic acid. [17,18] In particular, we have isolated and characterized the major strigolactones present in corn, namely zealactone and zeapyranolactone (Fig. 4).[18] This might have significant relevance for structural requirements for high activity of synthetic strigolactones in corn.

\section{Stereoselective Synthesis of GR24 Derivatives Using Keteneiminium salts as Key Intermediates}

As a general approach toward the stereoselective synthesis of GR24 derivatives, we designed an approach using intramolecular [2+2] cycloaddition of ketenes (Scheme 1). ${ }^{[4,10,19]}$ GR24 is an unnatural strigolactone used as standard in this field, which mimics in many instances the activity of canonical natural strigolactones. ${ }^{[20]}$

The cyclisation of the phenyl substituted ketene intermediate 2 was disappointing, leading initially only to $7 \%$ of the desired cyclobutanone 3. ${ }^{[19 \mathrm{~b}]}$ This reflects the ambident reactivity of ketenes having a low lying LUMO with a large coefficient on $\mathrm{C}(1)$ and nucleophilic lone pairs on oxygen and a nucleophilic center with a large coefficient in the HOMO on $\mathrm{C}(2)$, leading to dimerization and oligomerization side reactions when the rate of cycloaddition is too low. ${ }^{[21]}$ By slow addition of $\mathrm{NEt}_{3}$ under more diluted conditions, we reached a satisfactory yield of $64 \%$ of the cylclobutanone 3 , which was transformed through regioselective Baeyer-Villiger oxidation, formylation and coupling with the bromobutenolide $\mathbf{5}$ into the $\alpha$ and $\beta$ epimers of GR24 that were readily separated by chromatography (Scheme 1). ${ }^{[19 b]}$

The access to GR24 has been largely improved by the use of the keteneiminium salts, which are much more reactive electrophiles than the corresponding ketenes having no nucleophilic group,

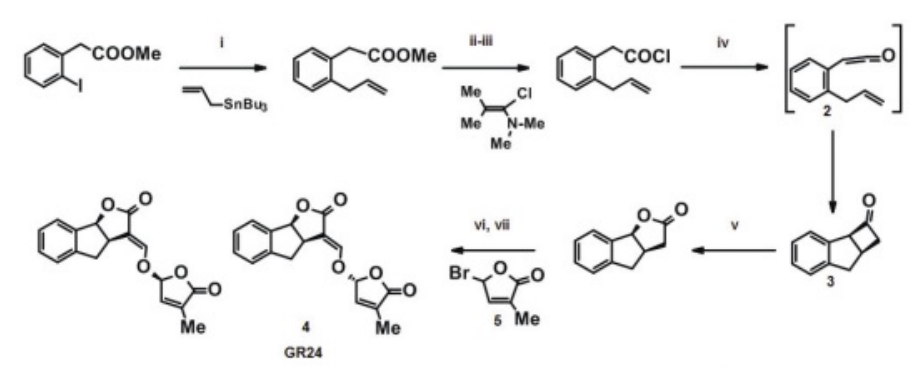

$\mathrm{i}=$ allyl n-tributyltin, $\mathrm{Pd}\left(\mathrm{PPh}_{3}\right)_{4}$ cat., toluene, reflux, $65 \%$; ii= LiOH, THF aq., RT, $98 \%$; iii= chloroenamine, $\mathrm{CH}_{2} \mathrm{Cl}_{2}, \mathrm{RT}, \mathrm{RT}$, $98 \%$; iv= $\mathrm{Et}_{3} \mathrm{~N}$ (addition in $4 \mathrm{~h}$ ), $\mathrm{CH}_{2} \mathrm{Cl}_{2}(0.02 \mathrm{M}), 40^{\circ} \mathrm{C}, 65 \%$; v= $\mathrm{AcOH}, \mathrm{H}_{2} \mathrm{O}_{2}$ aq. $(30 \%), 0^{\circ} \mathrm{C}, 90 \%$; vi $=\mathrm{HCOOMe}$, tBuOK, THF, RT, $68 \%$; vii= bromobutenolide 5, THF, tBuOK, RT, $80 \%$ (separation of diastereoisomers)

Scheme 1. Intramolecular ketene cycloaddition for the synthesis of GR24.[19b]

preventing their dimerization/oligomerization. ${ }^{[19 b, 22]}$ However, the use of the $\mathrm{NMe}_{2}$-substituted keteneiminium 7, generated by treatment of the amide $\mathbf{6}$ with triflic anhydride followed by collidine, was not regioselective due to some head-to-tail cycloaddition (Scheme 2). This unprecedented result for terminal $\mathrm{C}=\mathrm{C}$ bond was overcome by the use of larger substituents on nitrogen, leading only to the desired derivative in very good yield (Scheme 3 ).

In the case of $N, N$-dibenzyl keteneiminium $\mathbf{8}$, a more favorable 9:1 ratio for the desired cyclobutanone 3 was obtained. The reaction is completely regioselective with the $N, N$-diisopropyl keteneiminium salt 9 giving only cyclobutanone $\mathbf{3}$ (Scheme 3 ).

Using the intramolecular keteneiminium strategy, we synthesized a very broad variety of substituted strigolactones carrying various substituents on most positions of the core structure of GR24, enabling us to establish a structure-activity relationship (SAR) for various biological activities. ${ }^{[4]}$

The importance of the relative and absolute stereochemistry of strigolactones for their activity on parasitic seeds to induce their germination has been demonstrated in few examples prior to our work. ${ }^{[7 \mathrm{a}-\mathrm{f}, 8]}$ However, the influence on various biological ac-
Scheme 2. Intramolecular keteneiminium cycloaddition for the synthesis of GR24. ${ }^{[19 b]}$



$\mathrm{i}=$ allyl n-tributyltin, $\mathrm{Pd}\left(\mathrm{PPh}_{3}\right)_{4}$ cat., toluene, reflux, 81\%; ii= $\left(\mathrm{CF}_{3} \mathrm{SO}_{2}\right)_{2} \mathrm{O}$, collidine, $\mathrm{CH}_{2} \mathrm{Cl}_{2}(0.05 \mathrm{M}), \mathrm{RT}$. $98 \%$; iii $=\mathrm{H}_{2} \mathrm{O}, \mathrm{CCl}_{4}$, reflux, $82 \%$ (2 steps); iv $=\mathrm{AcOH}, \mathrm{H}_{2} \mathrm{O}_{2}$ aq. $(30 \%), 0^{\circ} \mathrm{C}, 90 \%$ 


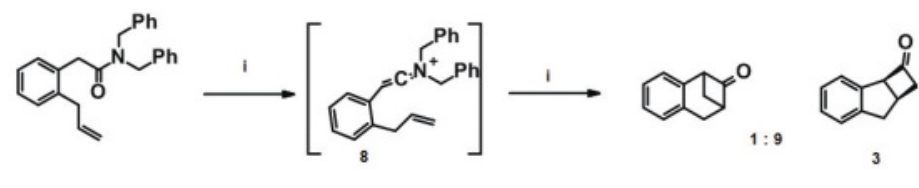

Scheme 3. Improved regioselectivity of the intramolecular [2+2] cycloaddition with bulky keteneiminium salts. ${ }^{[19 b]}$

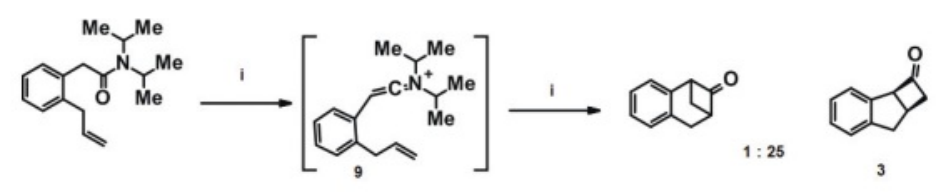

$\mathrm{i}=\left(\mathrm{CF}_{3} \mathrm{SO}_{2}\right)_{2} \mathrm{O}$, collidine, $\mathrm{CH}_{2} \mathrm{Cl}_{2}(0.05 \mathrm{M}), \mathrm{RT}$, ii $=\mathrm{H}_{2} \mathrm{O}, \mathrm{CCl}_{4}$, reflux, $71-74 \%(2$ steps)

tivities of strigolactones derivatives on crops was not known. We have accessed the four stereoisomers of GR24 using a chiral auxiliary on the nitrogen atom of the keteneiminium salt (Scheme 4), as shown previously by Ghosez on simple model structures. ${ }^{[22 a]}$ We were pleased to obtain high enantioselective formation of the cyclobutanones $\mathbf{3}$ using the optically pure dimethyl pyrrolidines substituted keteneiminium salt 10. Following oxidation, formylation and coupling with the bromobutenolide $\mathbf{5}$, the two diastereoisomers of GR24 have been obtained on gram scale, allowing the determination of their binding affinity for strigolactones receptors in vitro and their in vivo biological activity not only for seed germination induction of parasitic weeds but more importantly in crops. ${ }^{[4,10,19]}$

\section{Stereoselective Synthesis of the Four Stereoisomers of 5-Deoxystrigol by Intramolecular Keteneiminium Cycloaddition}

GR24 is the standard used in the field of strigolactones for most in vitro and in vivo biological studies. However, GR24 is a synthetic derivative which has different properties than the natural strigolactones, for example for their binding to recep- tors and for their recognition by proteins involved in their active transport. ${ }^{[23]}$ Consequently, it is essential to have access to natural strigolactones and evaluate their biological performance in crop plants.

In our first approach to 5-deoxystrigol as key biosynthetic intermediate for most canonical strigolactones, we used vinylketenes in intramolecular [2+2] cycloaddition (Scheme 5).[19a] We observed that only one isomer of the $\alpha$ - $\beta$-unsaturated acyl chloride obtained from the carboxylic acid $\mathbf{1 1}$ underwent the desired cyclization reaction. A mechanistic study (supported by $\left.{ }^{1} \mathrm{H}-\mathrm{NMR}, \mathrm{IR}\right)$ revealed the importance of the conformation adopted by the two geometric isomers around the $\mathrm{C}=\mathrm{C}$ bond and in particular the orientation of the $\gamma-\mathrm{C}-\mathrm{H}$ bond, which should be parallel to the $\pi$-orbitals of the $\mathrm{C}=\mathrm{C}$ bond and of the coplanar acyl chloride residue to facilitate the formation of the ketene by treatment with $\mathrm{NEt}_{3}$. In the case of the acyl chloride derived from 11, the $\gamma-\mathrm{C}-\mathrm{H}$ bond adopts an axial orientation parallel to the $\mathrm{C}=\mathrm{C}$ and $\mathrm{C}=\mathrm{O}$ bonds, which are not exactly coplanar. In contrast, for the acyl chloride derived from 12, the allyl group is oriented axially and the equatorial $\gamma-\mathrm{C}-\mathrm{H}$ bond cannot undergo an efficient $\mathrm{E}_{2}$ elimination by treatment with $\mathrm{NEt}_{3}$ due to its unfa-
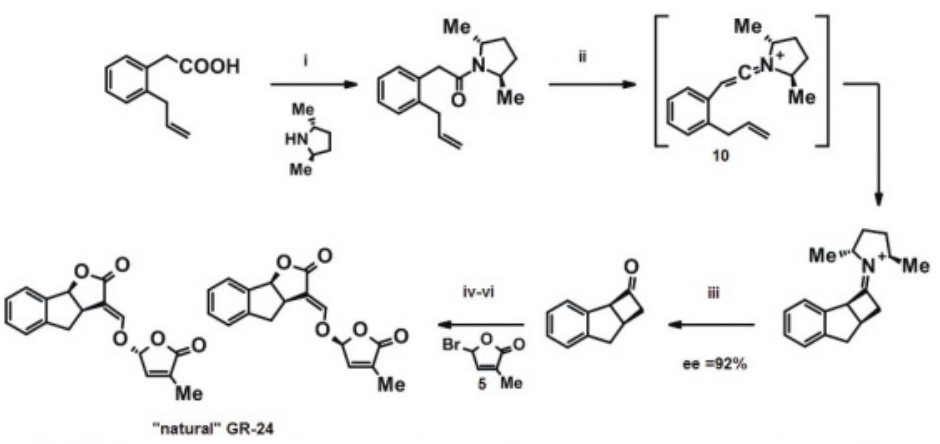

i= N-ethlyl $\mathrm{N}$-n-propyldimethylamino carbodiimide, $\mathrm{N}$-hydroxybenzotriazole, $\mathrm{NEt}_{3}, \mathrm{DMF}, \mathrm{RT}, 93 \%$; ii $=\mathrm{Tf}_{2} \mathrm{O}$, collidine, $\mathrm{CH}_{2} \mathrm{Cl}_{2}(0.05 \mathrm{M}), \mathrm{RT}$, iii $=\mathrm{H}_{2} \mathrm{O}, \mathrm{CCl}_{4}$, reflux, $68 \%$ (2 steps); iv= AcOH, $\mathrm{H}_{2} \mathrm{O}_{2}$ aq. $(30 \%), 0^{\circ} \mathrm{C}, 92 \%$, ee $=92 \%$; v $=\mathrm{HCOOMe}$, tBuOK, THF, RT, vi= bromobutenolide $5, \mathrm{THF}$, tBuOK, RT, (separation of diastereoisomers), $40 \%$ (2 steps).

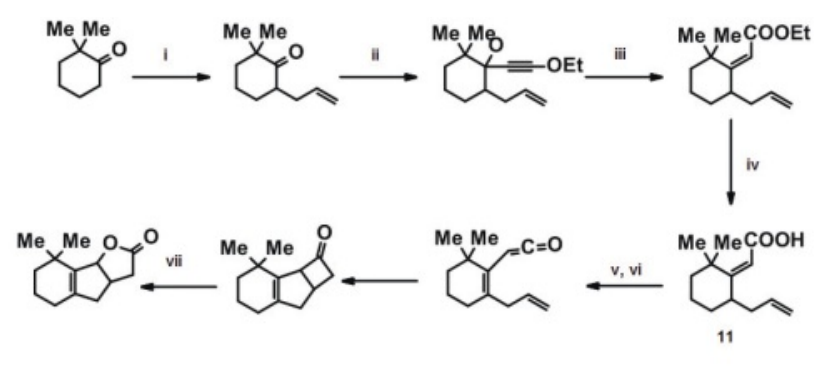

$\mathrm{i}=\mathrm{LiHMDS}$, allylbromide, THF, $-78^{\circ} \mathrm{C}, 65 \%$; ii = ethoxyacetylene, n-BuLi, THF, $78^{\circ} \mathrm{C}, 77 \%$; iii $=\mathrm{Sc}(\mathrm{OTf})_{3}$ cat., $\mathrm{CH}_{2} \mathrm{Cl}_{2}, \mathrm{ETOH}, 82 \%, \mathrm{E} / \mathrm{Z}=1: 1$, separation of isomers; iv $=\mathrm{NaOH}, \mathrm{THF} / \mathrm{H}_{2} \mathrm{O}, 95 \%$; $=$ chloroenamine, $\mathrm{CH}_{2} \mathrm{Cl}_{2}, \mathrm{RT}$; vi $=\mathrm{Et}_{3} \mathrm{~N}$, DMAP, $\mathrm{CH}_{2} \mathrm{Cl}_{2}$, reflux, $46 \%$; vii $=\mathrm{H}_{2} \mathrm{O}_{2}, \mathrm{AcOH}, 92 \%$.
Scheme 4. Asymmetric synthesis of GR24.[19b]

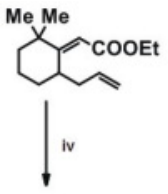

Scheme 5. Intramolecular ketene cycloaddition influenced by conformational restrictions for the synthesis of 5-deoxystrigol precursors. ${ }^{[19 a]}$ 
vorable orientation towards the coplanar $\mathrm{C}=\mathrm{C}$ and $\mathrm{C}=\mathrm{O}$ moieties (Scheme 5).[19a]

In the case of the corresponding amides 13 and 14, similar conformational constraints are operating. Moreover, we observed that keteneiminiums were quantitatively quenched by nucleophilic bases as $\mathrm{NEt}_{3}$ and $\mathrm{EtN}(\mathrm{iPr})_{2}$ and therefore only non-nucleophilic bases such as lutidine and collidine can be used. However, lutidine/collidine are not basic enough to form a vinylketeneiminium by elimination of the $\gamma$-hydrogen independently of its orientation toward the acrylamide moiety (Scheme 6).[19a]

Consequently, we modified our strategy by using an allylic acyl chloride in which the $\alpha$-hydrogen is activated for its elimination by the adjacent $\mathrm{C}=\mathrm{C}$ bond and by the acyl chloride (Scheme 7).

Similarly, the corresponding vinylketeneiminium of $\mathbf{1 5}$ was formed from the allylamide and the desired racemic cyclobutanone 16 was isolated in high yield. ${ }^{[19 a]}$

Using the $(S, S)$ - and the $(R, R)-2,5$ bis (methoxymethyl)-pyrrolidine amides, the four stereoisomers of 5-deoxystrigol were synthesized stereoselectively for the first time on gram scale and were evaluated in various biological tests (Scheme 8). This has been a crucial milestone for the project allowing us to investigate the mechanism of action of strigolactones for example in corn, underlining that GR24 has to be considered with great caution as standard in this field.

\section{Strigolactams as Novel Potent Analogues of Strigolactones}

A major restriction to the use of strigolactones for agricultural application is their relative instability in soil. At the beginning of our project only very fragmentary and qualitative data were available concerning the half-lives of strigolactones in representative biologically active soils. ${ }^{[7 a-f, 8,24]}$ We devoted intensive efforts to establish analytical methods and experimental procedures to follow soil metabolism of strigolactones. ${ }^{[10,25]}$

We determined that the half-life time of GR24 in soil was as short as 1.9 hour (Fig. 5), preventing its efficient use for various biological applications (seed treatment, drench application). ${ }^{[10,25]}$ The degradation of GR24 arises mainly from enzymatic cleavage of the butenolide ring (D-ring) and to a lesser extend of the enol ether linkage between the $\mathrm{C}$-D rings.

We designed the novel strigolactams in order to retain and even improve the very high biological activity of the corresponding lactones by forming stronger hydrogen bonds in the binding site and by stabilizing them towards enzymatic degradation. ${ }^{[19 d]}$ Strigolactams display indeed strong biological activities, frequently superior to the corresponding strigolactones. Improved water solubility and soil persistence have been reached with the strigolactams, which was further optimized by specific structural modifications. We identified strigolactams
Scheme 6. Attempted [2+2]cycloaddition of keteneiminium salts of $\alpha$ - $\beta$-unsaturated amides 13 and $14{ }^{[19 a]}$

Scheme 7. Efficient generation of the vinylketene 15 and its cyclization through [2+2] cycloaddition. ${ }^{[19 a]}$

Scheme 8. Stereoselective synthesis of the four stereoisomers of 5-deoxystrigol. ${ }^{[19 a]}$
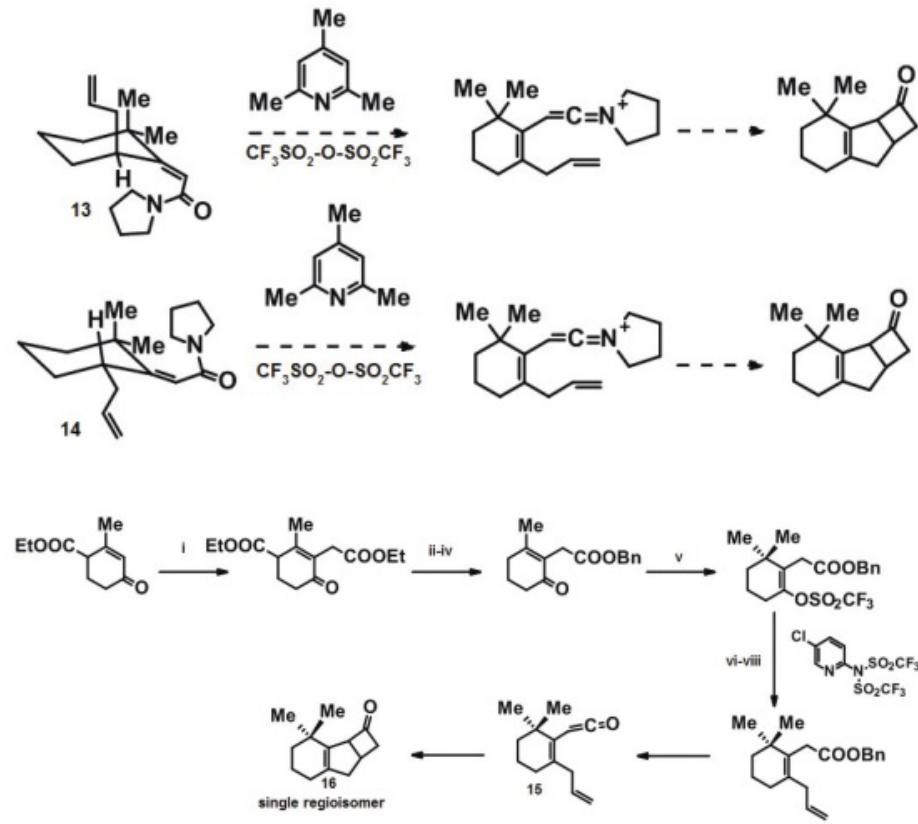

i = NaOEt, EtOH, bromoethylacetate, $98 \%$; ii = NaOH, ETOH, $\mathrm{H}_{2} \mathrm{O}$, then $\mathrm{HCl}$, RT; iii = toluene, DMF, reflux iv $=\mathrm{CS}_{2} \mathrm{CO}_{3}$, benzylbromide, $\mathrm{DMF}, 86 \% ; \mathrm{V}=\mathrm{MeLi}$, Cul, ether, $0^{\circ} \mathrm{C}$, then ketone addition, $-20^{\circ} \mathrm{C}$, then $\mathrm{Com}$ ! reagent, $\mathrm{THF}, 0^{\circ} \mathrm{C}, 98 \%$; vi $=$ allyltributyl stannane, $\mathrm{Pd}\left(\mathrm{PPh}_{3}\right)_{4}, \mathrm{LiCl}$, dioxane, reflux, 90\%; vii $=\mathrm{NaOH}$, diox $\mathrm{H}_{2} \mathrm{O}$, reflux, 86\%; viii = chloroenamine, $\mathrm{CH}_{2} \mathrm{Cl}_{2}, \mathrm{RT}$, then $\mathrm{Et}, \mathrm{N}$, reflux, $82 \%$.


$\mathrm{i}=\mathrm{Tf}_{2} \mathrm{O}, 2$-fluropyridine, $\mathrm{CH}_{2} \mathrm{Cl}_{2}, \mathrm{RT}$; ii $=\mathrm{H}_{2} \mathrm{O}, \mathrm{CCl}$, reflux, 85\%; iii $=\mathrm{H}_{2} \mathrm{O}_{2}, \mathrm{ACOH}, \mathrm{O}^{\circ} \mathrm{C}-\mathrm{RT}, 12 \mathrm{~h}$ $87 \%$; iv = tBuOK, HCOOMe, THF, RT; $v$ = chlorobutenolide, THF, RT, 85\% 
displaying half-lives in soil sufficient to allow their use for soil applications.

Strigolactams were synthesized from cyclobutanone $\mathbf{3}$ obtained by intramolecular keteneiminium cycloaddition (Scheme 9). Initially, the Beckmann rearrangement of the mesitylene sulfonyl oxime 17, or treatment under anhydrous conditions of cyclobutanone 3 with mesitylene $O$-sulfonyl hydroxylamine $(\mathrm{MSH})$, led to a mixture of regioisomers $\mathbf{1 8 , 1 9}$ and mainly to fragmentation into the corresponding nitrile 20. ${ }^{[19 \mathrm{~d}]}$ We have investigated this transformation in detail on various substrates because of its strategic implications for strigolactam synthesis. We discovered that the Beckmann rearrangement can be performed in high yield and high regioselectivity by the use of $\mathrm{MSH}$ in the presence of aqueous $\mathrm{HCl} .{ }^{[19 c]}$ Our experimental and theoretical studies support the hypothesis that the ring extension reaction occurs at the level of the tetrahedral intermediate resulting from the nucleophilic addition of $\mathrm{MSH}$ on cyclobutanone $3 .^{[19 c]}$ The transition state for the ring extension step involves a molecule of water and acid. This improvement of the Beckmann rearrangement to facilitate the regioselective synthesis of $\gamma$-lactams without fragmentation into the corre- sponding nitrile has found broad applications beyond the reaction of cyclobutanones. ${ }^{[19 c]}$

Among the various biological activities that we observed for the strigolactams, they are more potent seed germination stimulants than the corresponding strigolactones in the case of Orobanche cumana that infects sunflower (Fig. 6).[26] For example, GR24 strigolactam was more effective than GR24 strigolactone.[19d]

We applied intra- and intermolecular ketenes and keteneiminium salts [2+2] cycloadditions to the synthesis of strigolactams having only a tricyclic B-C-D scaffold. ${ }^{[10]}$ These compounds are readily synthesized on large scale and display improved physicochemical properties such as higher water solubility and lower $\log \mathrm{P}$ compared to GR24 and the corresponding tetracylic lactam and retain very high biological activity, as exemplified by selected results on seed germination induction of Orobanche cumana (Fig. 7). ${ }^{[10]}$

In addition to these results of seed germination of parasitic weeds, we developed a solid platform of various in vitro tests to evaluate the binding affinity of strigolactones/strigolactams to the D14 receptor in corn, as well as all plant assays in the laboratory and in green house and field. These achievements will be described separately.

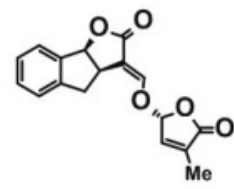

GR-24

$\log P 2.20$

Water solubility $9.5 \mathrm{ppm}$

Soil persistence $\mathrm{DT}_{50} 1.9 \mathrm{~h}$



Stronger bond

$\log P 1.99$

Water solubility $21.4 \mathrm{ppm}$

Soil persistence $\mathrm{DT}_{50} 3.5 \mathrm{~h}$



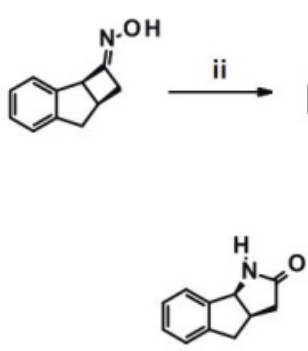

$18 ; 8 \%$


19; $8 \%$

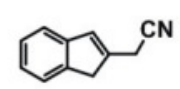

$20 ; 65 \%$
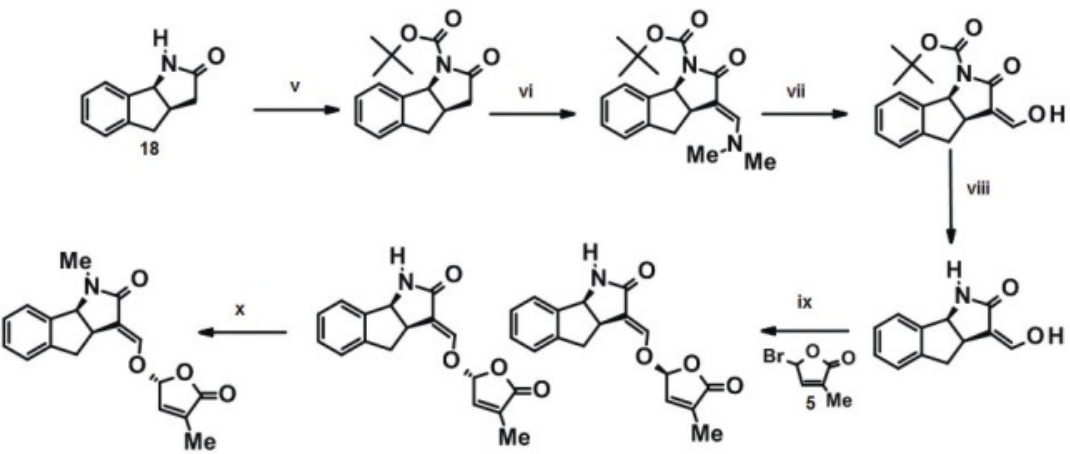

N.

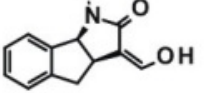

i= hydroxylamine. $\mathrm{HCl}, \mathrm{ACONa}, \mathrm{MeOH}, 83 \%$ (E,Z); ii = LiOH, THF, mesitylenesulfonylchloride, THF, reflux, 30\%; $\mathrm{iii}=\mathrm{Al}_{2} \mathrm{O}_{3}, \mathrm{MeOH}, \mathrm{RT}$; iv = $\mathrm{HCl}$ aq. $(2 \mathrm{M}), \mathrm{CH}_{2} \mathrm{Cl}_{2}, \mathrm{RT}$; v = BOC anhydride, DMAP, Et ${ }_{3} \mathrm{~N}, \mathrm{RT}, 97 \%$; vi = tbutoxybis-(dimethylamino)-methane, neat, $110^{\circ} \mathrm{C}$; vii $=\mathrm{HCl}(1 \mathrm{M})$, THF, $\mathrm{RT}, 80 \%$; viii $=\mathrm{TFA}, \mathrm{CH}_{2} \mathrm{Cl}_{2}, 0^{\circ} \mathrm{C}, 86 \%$; ix = bromobutenolide 5, tBuOK, THF, RT, 64\%; $x=\mathrm{NaH}, \mathrm{Mel}, \mathrm{DMF}, \mathrm{RT}, 50 \%$. 
Fig. 6. Orobanche cumana seed germination induction by strigolactam and strigolactone GR24. ${ }^{[19 c]}$ Second column: \%germination.



Dose $\left(\mathrm{mg} \cdot \mathrm{I}^{-1}\right)$



$10^{-4}$

$10^{-5}$

$10^{-6}$

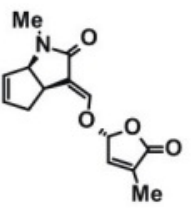

106

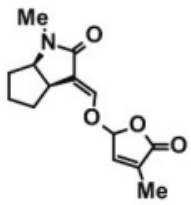

29

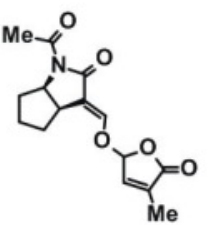

228
24.6

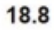

18.4

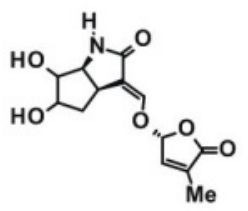

147

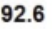

79.6

31.6

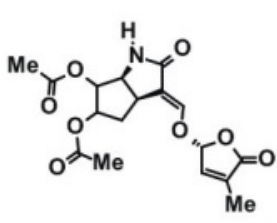

2471

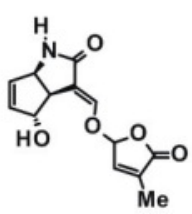

none
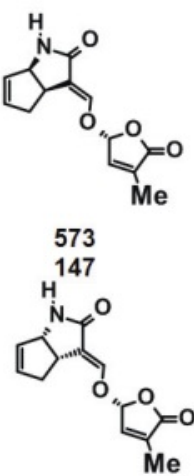

none

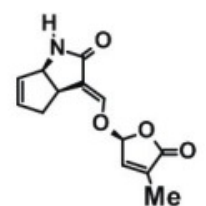

82



none

\section{Synthesis of Non-canonical Strigolactones}

Canonical strigolactones having the A-B-C-D four rings structure are biosynthesized in planta from $\beta$-carotene through carlactone, which is oxidized into carlactonoic acid and methyl carlactanoate as key intermediates. ${ }^{[17]}$ In many plant species, carlactonoic acid is transformed into 5-deoxystrigol and/or 4-deoxyorobanchol, which are further processed into the various canonical strigolactones (Fig. 8).[17] However, there are rather few examples of non-canonical structures such as heliolactone, which has been isolated from sunflower and avenaol isolated from Avena strigosa. ${ }^{[18 c, 27]}$ Remarkably, the major strigolactone exuded from maize roots was a non-canonical strigolactone, zealactone. ${ }^{[18 a]}$ The other maize strigolactone characterized so far is zeapyranolactone, which has a zealactone-like, non-canonical strigolactone structure. ${ }^{[18 b]}$

Carlactonoic acid and methyl carlactonoate are essential biosynthetic key intermediates but might play additional roles in planta. ${ }^{[28]}$ Biological studies are still needed to understand their multiple roles but are severely impaired by the lack of an efficient synthesis of carlactonoic acid and methyl carlactonoate. ${ }^{[28]}$ 


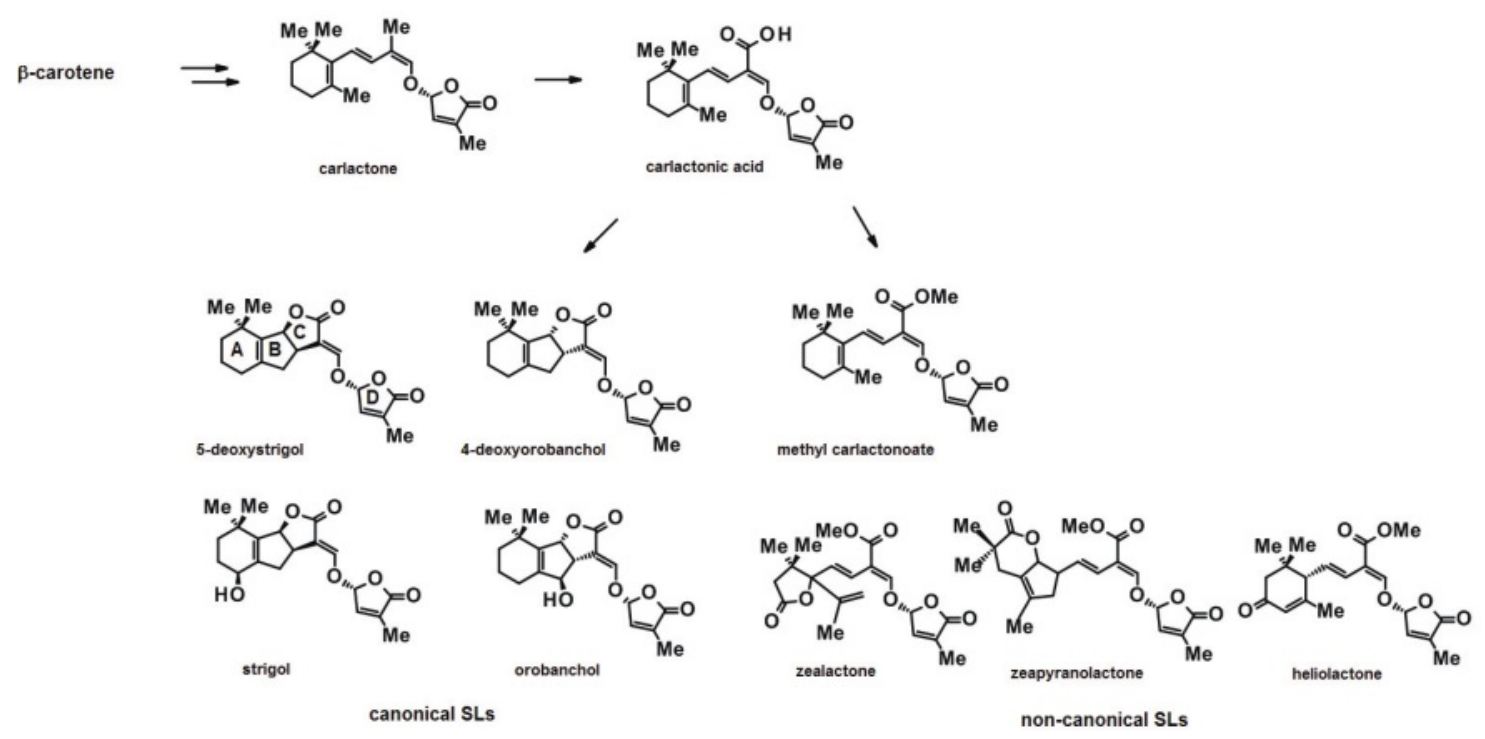

Fig. 8. Pivotal role of carlactonoic acid in strigolactones biosynthesis. ${ }^{[17,18,28]}$

Moreover, these compounds could be used as pro-cide in a given crop to produce, in planta, strigolactones specific to this species and even to tissue. For these reasons we have developed a novel efficient synthesis of carlactonoic acid and methyl carlactonoate, including deuterated derivatives to facilitate the biological studies in planta. ${ }^{[28]}$

The key building block is the iodo derivative $\mathbf{2 3}$ (Scheme $10)$, which has been obtained on multigram scale by addition of the butenolide 22 to methylpropiolate $\mathbf{2 1}$ followed by iodination of the push-pull $\mathrm{C}=\mathrm{C}$ bond and capture of the intermediate oxonium ion by $\mathrm{AcOH}$. The elimination of acetic acid is performed with $\mathrm{NEt}_{3}$ in very good overall yield. Both enantiomers of $\mathbf{2 3}$ could be readily separated by preparative chiral HPLC and fully characterized by CD-spectra and X-ray structure analysis. [28]

The other half of the molecule, the vinylstannane $\mathbf{2 4}$, has been efficiently prepared from $\beta$-cyclocitral by alkynylation and stannylation. Stille coupling of both residues $\mathbf{2 3}$ and $\mathbf{2 4}$ was accomplished on multigram scale with $\mathrm{Pd}_{2}(\mathrm{dba})_{3}$ and
$\mathrm{AsPh}_{3}$ as catalyst (Scheme 11) without racemization of the $R$ or $S$ stereochemistry arising from the corresponding optically pure iodide 23. ${ }^{28]}$

Following essentially the same scheme, two deuterated forms of methyl carlactonoate $\mathbf{2 6}$ and $\mathbf{2 7}$ were obtained in high yield and high deuterium content $(>90 \%)$. Such labeled compounds are instrumental for tracing their fate in plants and as internal standard for quantification by LC-MS/MS (Fig. 9).[28]

We achieved the synthesis of the corresponding aldehyde of carlactonoic acid $\mathbf{2 9}$ as potential novel biosynthetic carlactonoic acid intermediate (Scheme 12). In addition, we obtained the desired carlactonoic acid $\mathbf{3 1}$ by Stille coupling of the unprotected iodo carboxylic acid $\mathbf{3 0}$ in good overall yield. [28]

The gram scale synthesis of carlactonoic acid and its methyl ester, the separation/isolation/characterization of their enantiomers and of corresponding deuterated derivatives has been a major achievement paving the way for biological studies to determine the transformation of these key intermediates in corn.

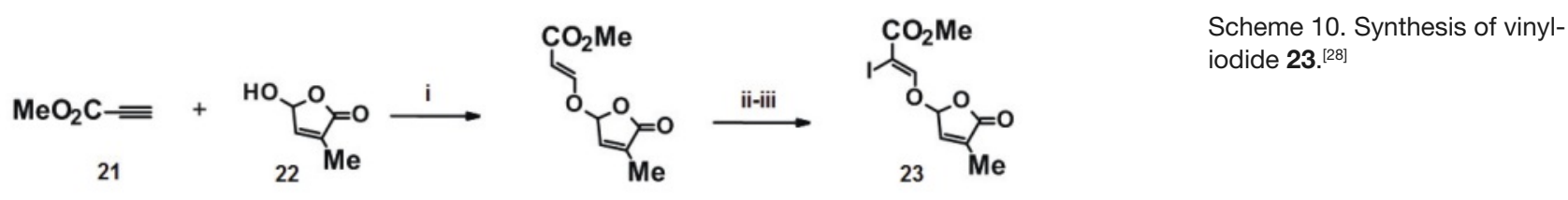

$\mathrm{i}=\mathrm{N}$-methylmorpholine, $\mathrm{THF}, \mathrm{RT}, 77 \%$; ii $=\mathrm{NIS}, \mathrm{AcOH}, \mathrm{CH}_{2} \mathrm{Cl}_{2}, \mathrm{RT}$; iii $=\mathrm{NEt}_{3}, \mathrm{RT}, 86 \%$

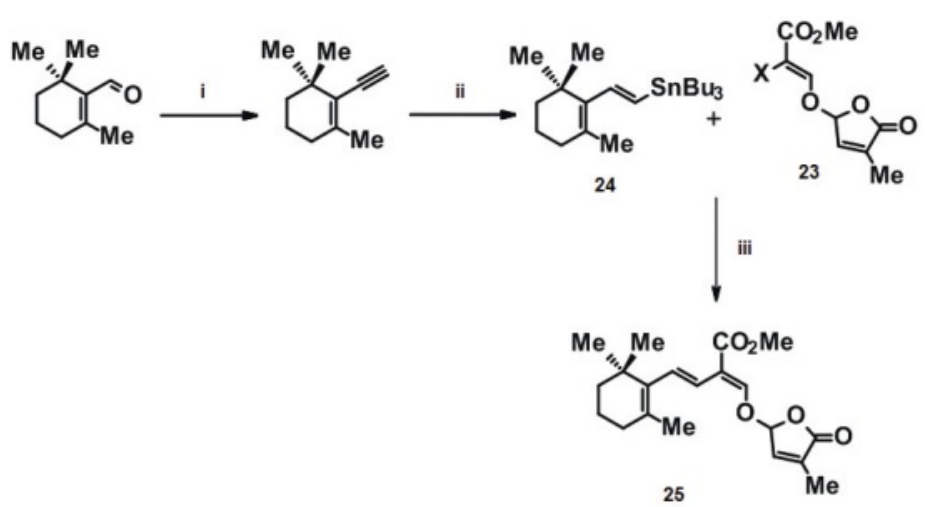

Scheme 11. Synthesis of the methyl carlactanoate 24. ${ }^{[28]}$ 


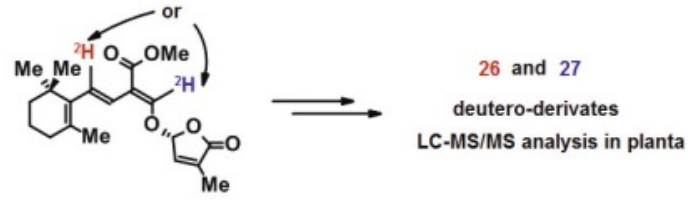

Fig. 9. Deuterium-labeled methyl carlactonoates. ${ }^{[28]}$

\section{Synthesis of Karrikins and their Evaluation as Seed Germination Inducers}

Karrikins are a small family of compounds produced by combustion of vegetation. ${ }^{[25,29]}$ These compounds are responsible for the strong seed germination induction observed after forest fire, which promotes vegetation recovery. Karrikin-1 (KAR-1) is the most abundant and representative compound of this class. KAR1 strongly induces at very low concentration seed germination of various 'fire-prompt' species. Moreover, it has been shown that karrikins bind to the D14-like1/KAI2 receptor, a homolog of the strigolactone receptor, D14. Consequently, karrikins have to be considered in close analogy to strigolactones for their potential uses in agriculture. In order to broadly evaluate the biological activity of karrikin derivatives, we developed a new synthetic pathway which is exemplified here for KAR-1 (Scheme 13). The key steps are the formylation of butenolide $\mathbf{3 2}$ followed by the 6-endo-dig cyclization into KAR-1 promoted by gold catalyst.[25]

Karrikins have been evaluated as seed germination inducers not only for non-parasitic weeds but also on various crops. Their ability to stimulate seed germination strongly differs from strigolactones. Contrary to what has been postulated in the literature, we demonstrated that KAR-1 does not promote seed germination of commercial corn varieties. ${ }^{[25]}$ The results previously described have used low germinating seed corn varieties, which have no commercial relevance. We also demonstrated that the corn seed uptake of KAR-1 is rather low and less favorable compared to GR24, for example, which might disfavor its ability to induce seed germination. ${ }^{[25]}$

\section{Further Applications of Keteneiminium Salts Chemistry for the Synthesis of Various Scaffolds}

The use of keteneiminium salts for intramolecular [2+2] cycloadditions to $\mathrm{C}=\mathrm{C}$ bonds allowed us to synthesize a very broad variety of strigolactone and strigolactam derivatives displaying very promising crop enhancement activities. ${ }^{[4,10,19 b-d]}$ Moreover, we have used very successfully keteneiminiums salts to synthesize various structures relevant to crop protection projects. [30] Although this is not the focus of the present publication related
Scheme 12. Synthesis of carlactonoic aldehyde 29 and carlactonoic acid 31. ${ }^{[28]}$

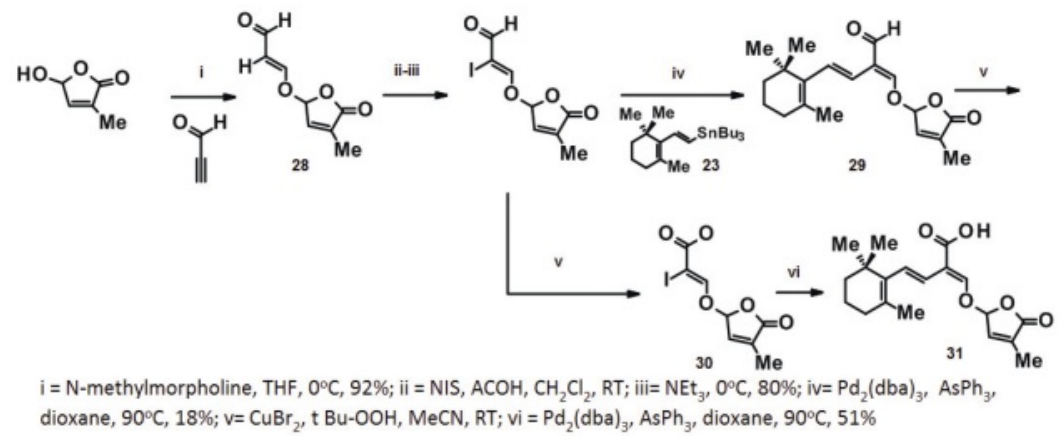

Scheme 13. Synthesis of karrikin-1 (KAR-1). ${ }^{[25]}$

Scheme 14. Applications of keteneimiums salts for the synthesis of various scaffolds. ${ }^{[22 c, 30,31]}$

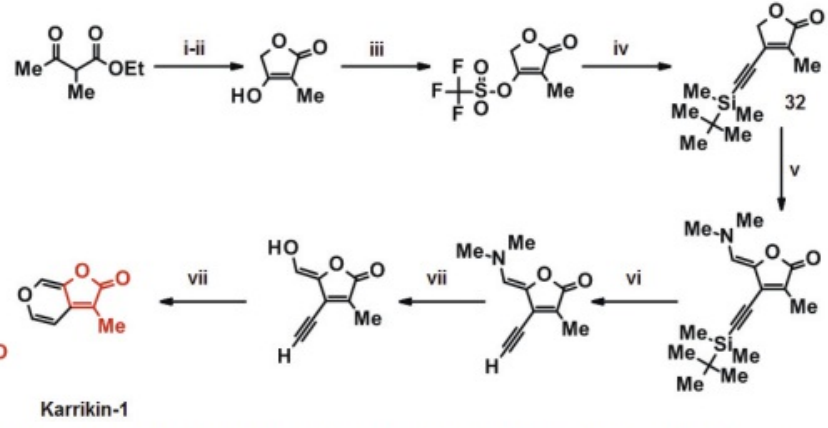

$$
\text { (+) strigol Me Karrikin-1 }
$$

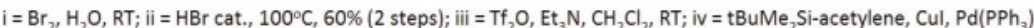
${ }_{2} \mathrm{Cl}_{2}$, diisopropylamine, dioxane, RT, $71 \%$ (2 steps); $\mathrm{v}=\mathrm{tBuO}-\mathrm{CH}-\left(\mathrm{NMe}_{2}\right)_{2}$, toluene, $\mathrm{RT}, 81 \%$; vi = KF, MeOH, reflux, 82\%; vii $=\mathrm{TsOH}, 0.05$ eq. $\mathrm{Au}-\mathrm{N}-\left(\mathrm{SO}_{2} \mathrm{CF}_{3}\right)_{2} \mathrm{PPh}_{3}, \mathrm{H}_{2} \mathrm{O}$, toluene, reflux, $67 \%$.

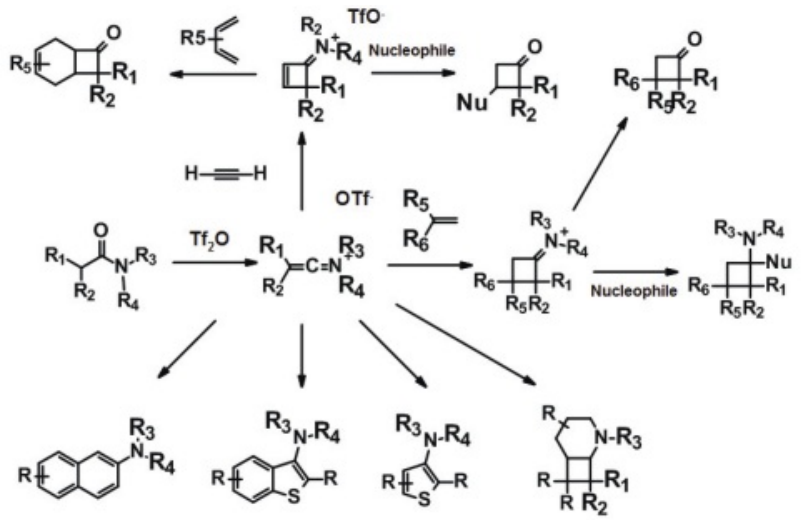


to the Sandmeyer Award, we summarize here briefly some results which have been recently disclosed (Scheme 14). ${ }^{[30]}$

Keteneiminium salts lead to cyclobutanones by addition to $\mathrm{C}=\mathrm{C}$ bonds and to cyclobuteneiminiums with acetylenes (Scheme 14). ${ }^{[22 e, 30 h, i, 31]}$ Cyclobuteneiminiums salts are very reactive dienophiles for Diels -Alder reaction ${ }^{[22 \mathrm{e}, 30 \mathrm{~h}, \mathrm{i}, 31]}$ as well as potent Michael acceptors for nucleophilic addition. ${ }^{[30 \mathrm{j}]}$ We demonstrated that cyclobutaneiminium salts react with organometallics to yield the corresponding amines. ${ }^{[30 \mathrm{a}, \mathrm{c}, \mathrm{d}]}$ The use of allyl protecting group on nitrogen allows the stereoselective synthesis of tertiary cyclobutane amines. Bicyclic amines can readily be obtained by intramolecular [2+2] addition of a keteneiminium salts carrying a $\mathrm{C}=\mathrm{C}$ bond in the side chain of the amine. ${ }^{[30 \mathrm{e}]}$ Polycyclic scaffolds are obtained stereoselectively when the amine side chain contains a $\mathrm{C}=\mathrm{C}$ bond incorporated into a 5 - or $6-\mathrm{mem}-$ bered ring. Moreover, aromatic rings can be generated starting from amides.[30b,f,j,k] Substituted naphthylamines, aminobenzothiophenes and aminothiophenes are readily accessible by $6 \pi$-electrocyclization reaction, at room temperature, from the corresponding $o$-styryl acetamides, vinylthioacetamides and thiophenylacetamides, respectively (Scheme 14). ${ }^{[30 \mathrm{~b}, \mathrm{f}, \mathrm{j}, \mathrm{k}]}$

\section{Conclusions}

Since the discovery of strigolactones as rhizosphere signaling molecules and further evidence that they play essential roles within plants as phytohormones, remarkable progress has been made in the understanding of their mode of action and their influence on various phenotypes under favorable and/or abiotic stress conditions. We mostly focused on gaining knowledge on their roles in crop plants, such as corn. To reach potential applications in modern agriculture, structural modifications of natural strigolactones are needed to stabilize them towards enzymatic degradation in planta and in soil. The multifunctional nature of strigolactones above and below ground to control several traits related to crop productivity opens new opportunities for innovation for a more sustainable agriculture.

We disclosed here some of the advances made to design and synthesize improved strigolactone analogs and to assess their biological profile in crop plants. Among them, strigolactams are very promising and have been efficiently synthesized thanks to the use of keteniminium salts as key intermediates for intramolecular [2+2] cycloadditions to $\mathrm{C}=\mathrm{C}$ bonds. The use of keteneiminium salts for the synthesis of other crop protection products has been intensively investigated and led to very promising synthetic methods.

\section{Acknowledgements}

We are very grateful for the key contributions of the following chemists who have actively supported the strigolactone and keteneiminium work in Syngenta and who are co-authors of previous publications: Drs. Amandine Kolleth, Emmanuelle Villedieu-Percheron, Didier Zurwerra, Pierre-Yves Dakas, Michael Dieckmann, Stefano Rendine and Professor Saron Catak (Bogazici University, Istanbul, Turkey).

Received: May 24, 2019

[1] a) E. C. Oerke, J. Agric. Sci. 2006, 144, 31, DOI: Doi: 10.1017/ s0021859605005708; b) J. Pretty, T. G. Benton, Z. P. Bharucha, L. V. Dicks, C. B. Flora, H. C. J. Godfray, D. Goulson, S. Hartley, N. Lampkin, C. Morris, G. Pierzynski, P. V. V. Prasad, J. Reganold, J. Rockström, P. Smith, P. Thorne, S. Wratten, Nat. Sustain. 2018, 1, 441, DOI: 10.1038/s41893018-0114-0; c) S. Savary, L. Willocquet, S. J. Pethybridge, P. Esker, N. McRoberts, A. Nelson, Nat. Ecol. Evol. 2019, 3, 430, DOI: 10.1038/s41559018-0793-y.

[2] T. Hák, S. Janou?ková, B. Moldan, Ecol. Indic. 2016, 60, 565, DOI: https:// doi.org/10.1016/j.ecolind.2015.08.003.

[3] C. Screpanti, R. Fonné-Pfister, A. Lumbroso, S. Rendine, M. Lachia, A. De Mesmaeker, Bioorg. Med. Chem. Lett. 2016, 26, 2392, DOI: https://doi. org/10.1016/j.bmcl.2016.03.072.

[4] M. Lachia, H. C. Wolf, A. De Mesmaeker, Bioorg. Med. Chem. Lett. 2014, 24, 2123, DOI: https://doi.org/10.1016/j.bmcl.2014.03.044.
[5] USDA, in 'Circular Series', Ed. U. S. D. A. Agriculture, 2017.

[6] C. E. Cook, L. P. Whichard, B. Turner, M. E. Wall, G. H. Egley, Science 1966, 154, 1189, DOI: 10.1126/science.154.3753.1189.

[7] a) C. Kannan, P. Aditi, B. Zwanenburg, Crop Prot. 2015, 70, 92, DOI: https:// doi.org/10.1016/j.cropro.2015.01.008; b) C. Kannan, B. Zwanenburg, Crop Prot. 2014, 61, 11, DOI: https://doi.org/10.1016/j.cropro.2014.03.008; c) C. Parker, Pest Manage. Sci. 2009, 65, 453, DOI: 10.1002/ps.1713; d) D. Rubiales, M. Fernandez-Aparicio, K. Wegmann, D. M. Joel, Weed Res. 2009, 49, 23, DOI: 10.1111/j.1365-3180.2009.00742.x; e) T. Spallek, M. Mutuku, K. Shirasu, Mol. Plant Pathol. 2013, 14, 861, DOI: 10.1111/mpp.12058; f) K. Yoneyama, A. A. Awad, X. Xie, K. Yoneyama, Y. Takeuchi, Plant Cell Physiol. 2010, 51, 1095, DOI: 10.1093/pcp/pcq055; g) B. Zwanenburg, T. Pospísil, Mol. Plant 2013, 6, 38, DOI: https://doi.org/10.1093/mp/sss141.

[8] B. Zwanenburg, A. S. Mwakaboko, A. Reizelman, G. Anilkumar, D. Sethumadhavan, Pest Manage. Sci. 2009, 65, 478, DOI: 10.1002/ps.1706.

[9] a) H. Samejima, A. G. Babiker, A. Mustafa, Y. Sugimoto, Front. Plant Sci. 2016, 7, DOI: 10.3389/fpls.2016.00634; b) B. Zwanenburg, A. S Mwakaboko, C. Kannan, Pest Manage. Sci. 2016, 72, 2016, DOI: 10.1002/ ps.4222.

[10] A. Lumbroso, E. Villedieu-Percheron, D. Zurwerra, C. Screpanti, M. Lachia, P.-Y. Dakas, L. Castelli, V. Paul, H. C. Wolf, D. Sayer, A. Beck, S. Rendine, R. Fonné-Pfister, A. De Mesmaeker, Pest Manage. Sci. 2016, 72, 2054, DOI: 10.1002/ps. 4268 .

[11] a) K. Akiyama, K.-i. Matsuzaki, H. Hayashi, Nature 2005, 435, 824, DOI 10.1038/nature03608 b) K. Akiyama, S. Ogasawara, S. Ito, H. Hayashi, Plant Cell Physiol. 2010, 51, 1104, DOI: 10.1093/pcp/pcq058; c) R. Aroca, J. M. Ruiz-Lozano, Á. M. Zamarreño, J. A. Paz, J. M. García-Mina, M. J. Pozo, J. A. López-Ráez, J. Plant Physiol. 2013, 170, 47, DOI: https://doi. org/10.1016/j.jplph.2012.08.020; d) H. J. Bouwmeester, C. Roux, J. A Lopez-Raez, G. Bécard, Trends Plant Sci. 2007, 12, 224, DOI: https://doi. org/10.1016/j.tplants.2007.03.009.

[12] a) A. Pineda, S.-J.Zheng, J. J. A. van Loon, C. M. J. Pieterse, M. Dicke, Trends Plant Sci. 2010, 15, 507, DOI: https://doi.org/10.1016/j.tplants.2010.05.007; b) R. Torres-Vera, J. M. García, M. J. Pozo, J. A. López-Ráez, Mol. Plant Pathol. 2014, 15, 211, DOI: 10.1111/mpp.12074.

[13] a) V. Gomez-Roldan, S. Fermas, P. B. Brewer, V. Puech-Pagès, E. A. Dun, J.P. Pillot, F. Letisse, R. Matusova, S. Danoun, J.-C. Portais, H. Bouwmeester, G. Bécard, C. A. Beveridge, C. Rameau, S. F. Rochange, Nature 2008, 455 , 189, DOI: 10.1038 /nature07271; b) M. Umehara, A. Hanada, S. Yoshida, K. Akiyama, T. Arite, N. Takeda-Kamiya, H. Magome, Y. Kamiya, K. Shirasu, K. Yoneyama, J. Kyozuka, S. Yamaguchi, Nature 2008, 455, 195, DOI: 10.1038/nature 07272

[14] a) S. Al-Babili, H. J. Bouwmeester, Annu. Rev. Plant Biol. 2015, 66, 161 DOI: 10.1146/annurev-arplant-043014-114759; b) P. B. Brewer, H. Koltai, C. A. Beveridge, Mol. Plant 2013, 6, 18, DOI: https://doi.org/10.1093/mp/ sss130; c) W. Kohlen, C. Ruyter-Spira, H. J. Bouwmeester, Botany 2011, 89, 827, DOI: 10.1139/b11-063; d) M. Lopez-Obando, Y. Ligerot, S Bonhomme, F.-D. Boyer, C. Rameau, Development 2015, 142, 3615, DOI: 10.1242/dev.120006; e) C. Screpanti, K. Yoneyama, H. J. Bouwmeester, Pest Manage. Sci. 2016, 72, 2013, DOI: 10.1002/ps.4436; f) Y. Seto, H. Kameoka, S. Yamaguchi, J. Kyozuka, Plant Cell Physiol. 2012, 53, 1843 , DOI: $10.1093 / \mathrm{pcp} / \mathrm{pcs} 142$

[15] E. Villedieu-Percheron, M. Lachia, P. M. J. Jung, C. Screpanti, R. FonnéPfister, S. Wendeborn, D. Zurwerra, A. De Mesmaeker, Chimia 2014, 68 , 654, DOI: 10.2533 /chimia.2014.654

[16] L. C. Carvalhais, V. A. Rincon-Florez, P. B. Brewer, C. A. Beveridge, P. G. Dennis, P. M. Schenk, Rhizosphere 2019, 9, 18, DOI: https://doi org/10.1016/j.rhisph.2018.10.002.

[17] a) S. Abe, A. Sado, K. Tanaka, T. Kisugi, K. Asami, S. Ota, H. I. Kim, K. Yoneyama, X. Xie, T. Ohnishi, Y. Seto, S. Yamaguchi, K. Akiyama, K. Yoneyama, T. Nomura, Proc. Natl. Acad. Sci. U.S.A. 2014, 111, 18084, DOI 10.1073/pnas.1410801111; b) A. Alder, M. Jamil, M. Marzorati, M. Bruno, M. Vermathen, P. Bigler, S. Ghisla, H. Bouwmeester, P. Beyer, S. Al-Babili, Science 2012, 335, 1348, DOI: 10.1126/science.1218094; c) N. Mori, K. Nishiuma, T. Sugiyama, H. Hayashi, K. Akiyama, Phytochemistry 2016 , 130, 90, DOI: https://doi.org/10.1016/j.phytochem.2016.05.012.

[18] a) T. V. Charnikhova, K. Gaus, A. Lumbroso, M. Sanders, J.-P. Vincken, A. De Mesmaeker, C. P. Ruyter-Spira, C. Screpanti, H. J. Bouwmeester, Phytochemistry 2017, 137, 123, DOI: https://doi.org/10.1016/j.phytochem.2017.02.010; b) T. V. Charnikhova, K. Gaus, A. Lumbroso, M Sanders, J.-P. Vincken, A. De Mesmaeker, C. P. Ruyter-Spira, C. Screpanti, H. J. Bouwmeester, Phytochem. Lett. 2018, 24, 172, DOI: https://doi org/10.1016/j.phytol.2018.01.003; c) K. Ueno, T. Furumoto, S. Umeda, M. Mizutani, H. Takikawa, R. Batchvarova, Y. Sugimoto, Phytochemistry 2014 108, 122, DOI: https://doi.org/10.1016/j.phytochem.2014.09.018

[19] a) M. Lachia, P.-Y. Dakas, A. De Mesmaeker, Tetrahedron Lett. 2014, 55 6577, DOI: https://doi.org/10.1016/j.tetlet.2014.10.040; b) M. Lachia, P. M J. Jung, A. De Mesmaeker, Tetrahedron Lett. 2012, 53, 4514, DOI: https:// doi.org/10.1016/j.tetlet.2012.06.013; c) M. Lachia, F. Richard, R. Bigler, A. Kolleth-Krieger, M. Dieckmann, A. Lumbroso, U. Karadeniz, S. Catak, A. De Mesmaeker, Tetrahedron Lett. 2018, 59, 1896, DOI: https://doi org/10.1016/j.tetlet.2018.03.012; d) M. Lachia, H. C. Wolf, P. J. M. Jung, 
C. Screpanti, A. De Mesmaeker, Bioorg. Med. Chem. Lett. 2015, 25, 2184, DOI: https://doi.org/10.1016/j.bmcl.2015.03.056.

[20] A. W. Johnson, G. Gowada, A. Hassanali, J. Knox, S. Monaco, Z. Razavi, G. Rosebery, J. Chem. Soc., Perkin Trans. 1 1981, 1734, DOI: 10.1039/ P19810001734.

[21] H. Saimoto, C. Houge, A.-M. Hesbain-Frisque, A. Mockel, L. Ghosez, Tetrahedron Lett. 1983, 24, 2251, DOI: https://doi.org/10.1016/S00404039(00)81896-1.

[22] a) L. Y. Chen, L. Ghosez, Tetrahedron Lett. 1990, 31, 4467, DOI: https:// doi.org/10.1016/S0040-4039(00)97650-0; b) E. J. Corey, M. C. Desai, T. A. Engler, J. Am. Chem. Soc. 1985, 107, 4339, DOI: 10.1021/ja00300a049; c) A. De Mesmaeker, S. J. Veenstra, B. Ernst, Tetrahedron Lett. 1988, 29, 459, DOI: https://doi.org/10.1016/S0040-4039(00)80121-5; d) A. Devos, J. Remion, A. M. Frisque-Hesbain, A. Colens, L. Ghosez, J. Chem. Soc., Chem. Commun. 1979, 1180, DOI: 10.1039/C39790001180; e) J. B. Falmagne, J. Escudero, S. Taleb-Sahraoui, L. Ghosez, Angew. Chem., Int. Ed. 1981, 20, 879, DOI: doi:10.1002/anie.198108791; f) L. Ghosez, I. Marko, A. M. Hesbain-Frisque, Tetrahedron Lett. 1986, 27, 5211, DOI: https://doi.org/10.1016/S0040-4039(00)85171-0; g) I. Marko, B. Ronsmans, A. M. Hesbain-Frisque, S. Dumas, L. Ghosez, B. Ernst, H. Greuter, J. Am. Chem. Soc. 1985, 107, 2192, DOI: 10.1021/ja00293a073; h) B. B. Snider, Chem. Rev. 1988, 88, 793, DOI: 10.1021/cr00087a005; i) S. J. Veenstra, A. De Mesmaeker, B. Ernst, Tetrahedron Lett. 1988, 29, 2303, DOI: https://doi. org/10.1016/S0040-4039(00)86043-8.

[23] a) T. Kretzschmar, W. Kohlen, J. Sasse, L. Borghi, M. Schlegel, J. B. Bachelier, D. Reinhardt, R. Bours, H. J. Bouwmeester, E. Martinoia, Nature 2012, 483, 341, DOI: 10.1038/nature10873; b) X. Xie, K. Yoneyama, T. Kisugi, T. Nomura, K. Akiyama, T. Asami, K. Yoneyama, J. Pestic. Sci. 2015, 40, 214, DOI: 10.1584/jpestics.D15-045.

[24] a) A. G. T. Babiker, A. M. Hamdoun, A. Rudwan, N. G. Mansi, H. H. Faki, Weed Res. 1987, 27, 173, DOI: 10.1111/j.1365-3180.1987.tb00751.x; b) A. G. T. Babiker, N. E. Ibrahim, W. G. Edwards, Weed Res. 1988, 28, 1, DOI: 10.1111/j.1365-3180.1988.tb00778.x.

[25] M. Lachia, R. Fonné-Pfister, C. Screpanti, S. Rendine, P. Renold, D. Witmer, A. Lumbroso, E. Godineau, D. Hueber, A. De Mesmaeker, Helv. Chim. Acta 2018, 101, e201800081, DOI: doi:10.1002/hlca.201800081.

[26] H. Koltai, New Phytol. 2011, 190, 545, DOI: 10.1111/j.14698137.2011.03678.x.

[27] H. I. Kim, T. Kisugi, P. Khetkam, X. Xie, K. Yoneyama, K. Uchida, T. Yokota, T. Nomura, C. S. P. McErlean, K. Yoneyama, Phytochemistry 2014, 103, 85, DOI: https://doi.org/10.1016/j.phytochem.2014.03.030.
[28] M. C. Dieckmann, P.-Y. Dakas, A. De Mesmaeker, J. Org. Chem. 2018, 83, 125, DOI: $10.1021 /$ acs.joc.7b02465

[29] a) B. Janssen, K. Snowden, Front. Plant Sci. 2012, 3, DOI: 10.3389/ fpls.2012.00296; b) D. C. Nelson, G. R. Flematti, E. L. Ghisalberti, K. W. Dixon, S. M. Smith, Annu. Rev. Plant Biol. 2012, 63, 107, DOI: 10.1146/ annurev-arplant-042811-105545.

[30] a) C. Battilocchio, G. Iannucci, S. Wang, E. Godineau, A. Kolleth, A. De Mesmaeker, S. V. Ley, React. Chem. Eng. 2017, 2, 295, DOI: 10.1039/ c7re00020k; b) D. Dagoneau, A. Kolleth, A. Lumbroso, G. Tanriver, S. Catak, S. Sulzer-Mossé, A. De Mesmaeker, Helv. Chim. Acta 2019, 102, e1900031, DOI: 10.1002/hlca.201900031; c) A. Kolleth, A. Lumbroso, G. Tanriver, S. Catak, S. Sulzer-Mossé, A. De Mesmaeker, Tetrahedron Lett. 2016, 57, 2697, DOI: https://doi.org/10.1016/j.tetlet.2016.04.092; d) A. Kolleth, A. Lumbroso, G. Tanriver, S. Catak, S. Sulzer-Mossé, A. De Mesmaeker, Tetrahedron Lett. 2016, 57, 3510, DOI: https:// doi.org/10.1016/j.tetlet.2016.06.097; e) A. Kolleth, A. Lumbroso, G. Tanriver, S. Catak, S. Sulzer-Mossé, A. De Mesmaeker, Tetrahedron Lett. 2017, 58, 2904, DOI: https://doi.org/10.1016/j.tetlet.2017.06.033; f) A. Kolleth, S. Müller, A. Lumbroso, G. Tanriver, S. Catak, S. SulzerMossé, A. De Mesmaeker, Tetrahedron Lett. 2018, 59, 3242, DOI: https://doi.org/10.1016/j.tetlet.2018.06.049; g) A. Lumbroso, J. Behra, A. Kolleth, P.-Y. Dakas, U. Karadeniz, S. Catak, S. Sulzer-Mossé, A. De Mesmaeker, Tetrahedron Lett. 2015, 56, 6541, DOI: https://doi. org/10.1016/j.tetlet.2015.09.103; h) A. Lumbroso, S. Catak, S. SulzerMossé, A. De Mesmaeker, Tetrahedron Lett. 2014, 55, 5147, DOI: https://doi.org/10.1016/j.tetlet.2014.07.059; i) A. Lumbroso, S. Catak, S. Sulzer-Mossé, A. De Mesmaeker, Tetrahedron Lett. 2014, 55, 6721, DOI: https://doi.org/10.1016/j.tetlet.2014.10.013; j) A. Lumbroso, S. Catak, S. Sulzer-Mossé, A. De Mesmaeker, Tetrahedron Lett. 2015, 56, 2397, DOI: https://doi.org/10.1016/j.tetlet.2015.02.112; k) E. Villedieu-Percheron, S. Catak, D. Zurwerra, R. Staiger, M. Lachia, A. De Mesmaeker, Tetrahedron Lett. 2014, 55, 2446, DOI: https://doi.org/10.1016/j.tetlet.2014.02.135.

[31] a) C. Hoornaert, A. M. Hesbain-Frisque, L. Ghosez, Angew. Chem., Int Ed. 1975, 14, 569, DOI: doi:10.1002/anie.197505691; b) J. MarchandBrynaert, L. Ghosez, J. Am. Chem. Soc. 1972, 94, 2870, DOI: 10.1021/ ja00763a062; c) C. Schmit, S. Sahraoui-Taleb, E. Differding, C. G. Dehasse-De Lombaert, L. Ghosez, Tetrahedron Lett. 1984, 25, 5043, DOI: https://doi.org/10.1016/S0040-4039(01)91114-1; d) A. Sidani, J. Marchand-Brynaert, L. Ghosez, Angew. Chem., Int. Ed. 1974, 13, 267, DOI: doi:10.1002/anie.197402671; e) F. Mahuteau-Betzer, P.-Y. Ding, L. Ghosez, Helv. Chim. Acta 2005, 88, 2022. 